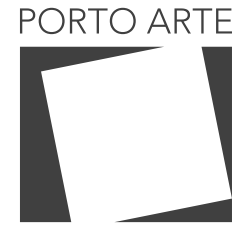

Revista de Artes Visuais

$\vee 25 n .44$

Jul/dez 2020 e-ISSN: 2179-8001

\title{
Quando a morte entra em cena: uma perspectiva inversa ${ }^{\mathbf{1}}$
}

When death takes the scene - a reverse perspective

\section{Maíra Gerstner}

ORCID: 0000-0002-1436-5292

Universidade de São Paulo, Brasil

\section{Resumo}

A partir do encontro entre os saberes do corpo, da arte e da clínica, surge o Teatro da Alma, trabalho estético-clínico desenvolvido dentro de um contexto terapêutico. Aqui serão apresentadas três cenas (duas fruto de experiências realizadas a partir do trabalho com o Teatro da Alma) nas quais a morte se fez presente revelando-se como uma intrigante fronteira, capaz de nos orientar, como um grande oráculo, pela turva floresta da vida. Além disso, o presente material também acompanha imagens e esquemas que revelam um pouco mais do trabalho.

Palavras- chave

Arte. Arte Contemporânea. Teatro. Corpo. Clínica. Morte.

\section{Abstract}

From the encounter between the knowledges of body, art and clinic, the Theater from the Soul emerges as an aesthetic-clinical work developed within a therapeutic context. Here, three scenes will be presented (two from experiences made from the work with the Theater from the Soul) in which death was present, revealing itself as an intriguing frontier, capable of guiding us, like a great oracle, through the murky forest of life. In addition, the present material also presents images and diagrams that reveal a little more of the work.

Keyworks

Arte. Contemporary Art. Theater. Body. Clinic. Death. 


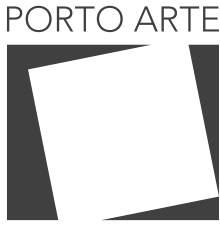

Revista de Artes Visuais

v. 25 n. 44 $\mathrm{Jul} / \mathrm{dez} 2020$ -ISSN: 2179-8001
A morte nos fará a todos teatrais, a despeito do que tenhamos feito ou não em vida.

Lionel Abel

Prólogo: Quais caminhos levam a arte à clínica? Há alguns anos tenho tido a oportunidade de investigar com profundidade o legado da artista brasileira Lygia Clark, sobretudo o que concerne à sua última fase. Fui desbravando, em paralelo, outras propostas terapêuticas que compreendem o ser na sua dimensão sistêmica. Neste sentido, o encontro com a Constelação Familiar, proposta por Bert Hellinger, fez com que eu vislumbrasse a cena como um um espaço onde a própria vida poderia vir a ser encarnada a fim de buscar deslocamentos sensíveis.

o Teatro da Alma, portanto, vem acontecendo através de exercícios, feitos em um contexto terapêutico onde o corpo já possui um protagonismo em termos escuta. A cena pode ser simbolizada através de um pedaço de papel, ou mesmo definida através de linhas no espaço. São pensadas algumas diretrizes de movimento nas quais o corpo, de forma sutil, pode vir a fazer contato com outros modos de operar diante de uma determinada questão.

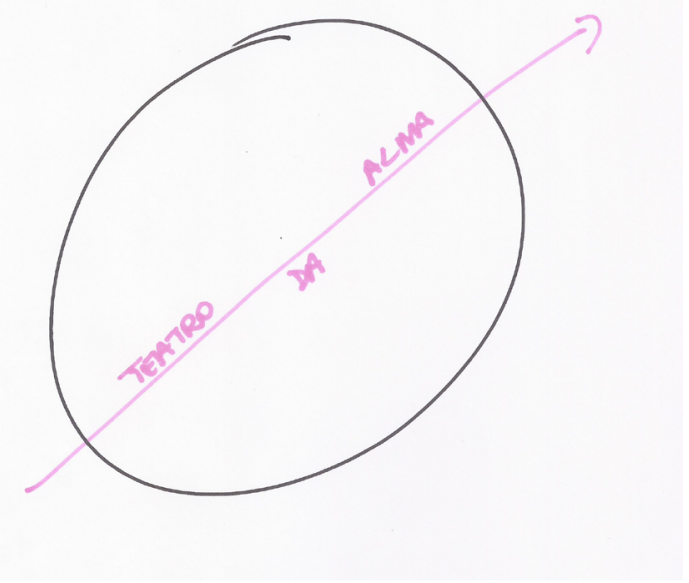

Figura 1: Teatro da Alma (2020)

\section{Cena 1: A morte das matriarcas}

"Quando uma pessoa querida morre, algo em nós morre também". As palavras do rabino ressoaram em mim como um rio que margeava um território distante, inabitado e desconhecido. Tínhamos chegado levemente atrasados e não pudemos abraçar ninguém por conta da pandemia. Era um lugar alto e todos estavam a postos como uma cena de um filme. E o que fica da vida após a sua morte? Um novo senso de comunidade se imantava ali. 


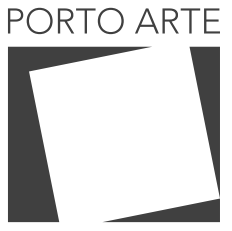

Revista de Artes Visuais

V.25 n. 44

Jul/dez 2020

Figura 2: Passado, Presente Fututo (2020)

Figura 3: A Roda da Vida (2020) Desenho

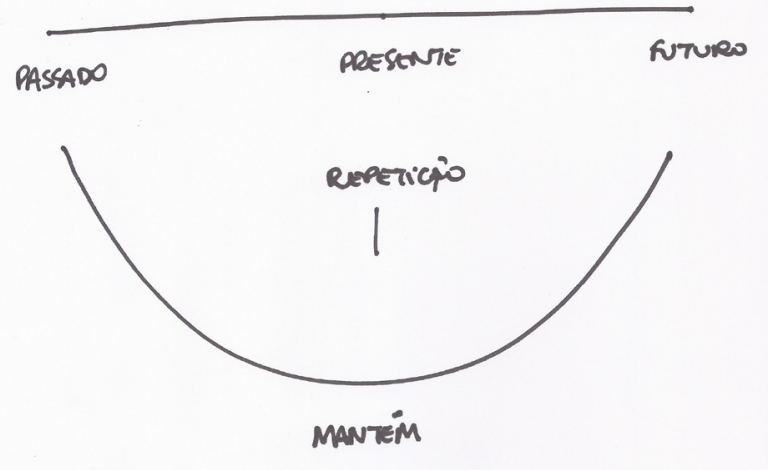

"Sua avó sofreu uma queda e será operada ainda hoje. A situação é delicada". Cinco meses depois recebo a seguinte mensagem e em dez dias minha avó estava sendo maquiada por mim, no caixão, para então ser enterrada. A morte entrou em cena de uma forma silenciosa e desta vez levou consigo, além de minha avó, algo meu que eu também precisava me despedir.

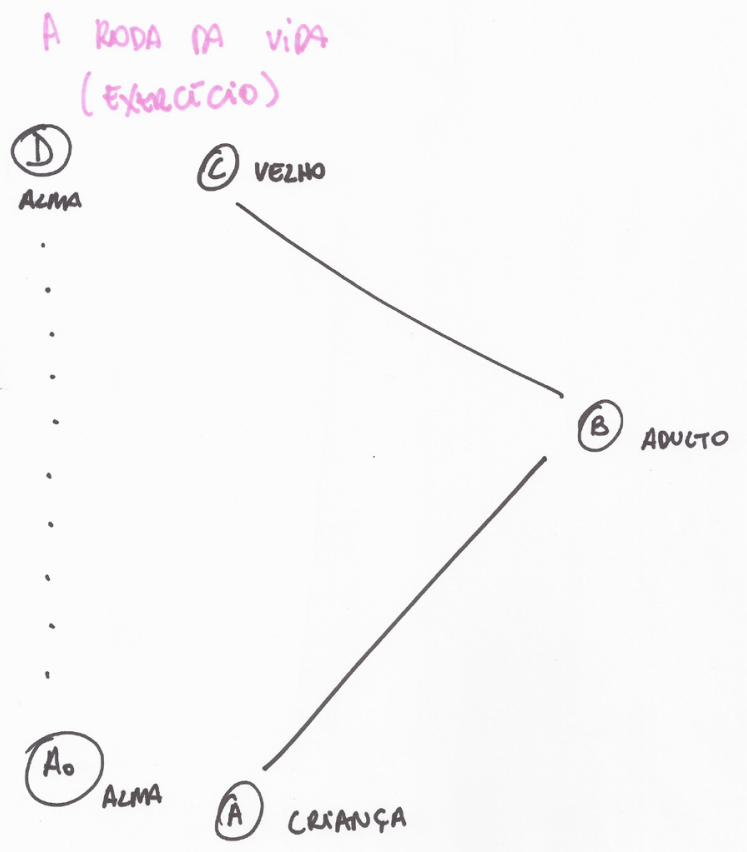

A morte de duas matriarcas, duas avós que não se conheceram em vida, mas que, tinham nascido no mesmo ano e agora, morriam no mesmo ano também, abriu espaço para que se lançasse um olhar curioso para que essa que adentra à cena da vida e tudo revira. 


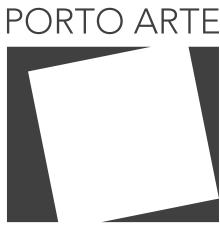

Revista de Artes Visuais

v $25 n \cdot 44$ $\mathrm{Jul} / \mathrm{dez} 2020$ e-ISSN: 2179-8001

\section{Cena 2: A morte do pai}

A morte prematura do pai atrelada ao diagnóstico de esquizofrenia fazia seu mar de emoções aflorar durante as sessões. Era assunto tabu na família. Aos poucos foi sendo possível desvelar alguns detalhes, sonhos, desejos e quereres de menina que não foram vividos.

Um ano depois Joana ${ }^{1}$ chega dizendo que havia se inscrito em um curso de teatro que tinha como objetivo a construção de solos a partir de temas pessoais e que iria olhar para a história do pai. Encorajei-a e fiquei no aguardo que poderia surgir. Ao passar do tempo ela foi trazendo suas dificuldades em abordar o assunto naquele contexto, não conseguia levar os materiais e estava se sentindo mal com isso. Foi então que propus: o que você acha de fazermos essa cena aqui?

\section{A MORTE do PRiMo}

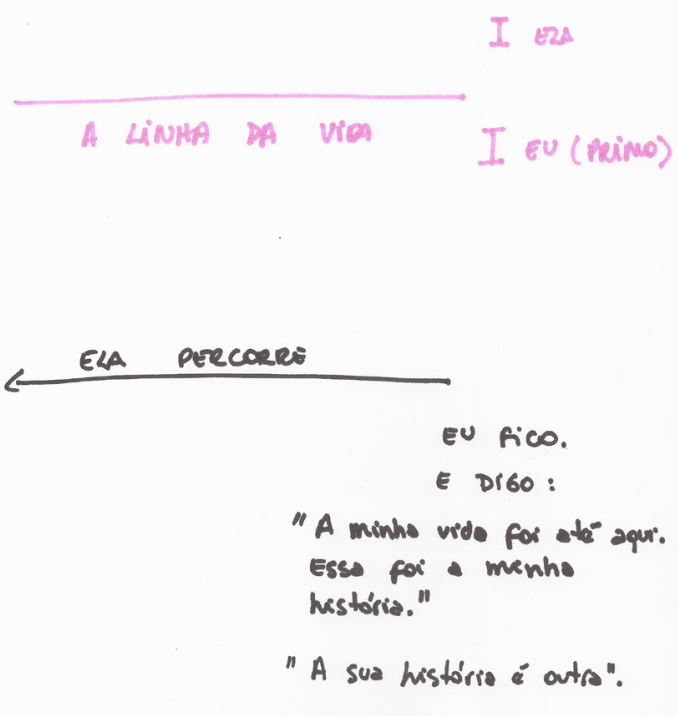

Iniciamos um processo de quatro meses de investigação de materiais: fotos, cartas, escrita criativa, associação com outros textos etc. Aos poucos os conteúdos que iam surgindo eram tanto materiais sensíveis para serem explorados no contexto da clínica como também materiais que iam compondo a cena. 


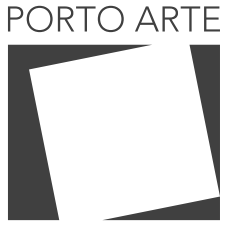

Revista de Artes Visuais

v. 25 n. 44 $\mathrm{Jul} / \mathrm{dez} 2020$ e-ISSN: 2179-8001

Foram convidadas para a partilha apenas algumas pessoas: duas tias e duas amigas. Ao entrar, éramos convidadas para nos sentarmos em roda. No chão uma mesa estava posta com frutas secas, uvas frescas e vinho. Ela havia desde o início trazido a situação de uma ceia de Natal como uma possibilidade para ambientar a experiência. Depois de comermos e rirmos juntas, ela foi se dirigindo pelos espaços da sala lendo textos de Clarice Lispector e Hilda Hilst. A última ação era a leitura de uma carta que ela havia escrito ao pai. "Minha mãe não fala no assunto".

Quando tudo terminou, na roda final, as tias de Joana tiveram o desejo de se colocar: uma delas, irmã do pai, falou da importância daquilo e quanto o seu pai a amava e também o quanto ele havia sofrido. Já a outra tia, irmã da mãe, trouxe a sua percepção sobre o silêncio da sua mãe e da dificuldade que ela tinha em falar do assunto pois the causava muito sofrimento.

\section{A ceNA COMO PANNTA BAIXA}

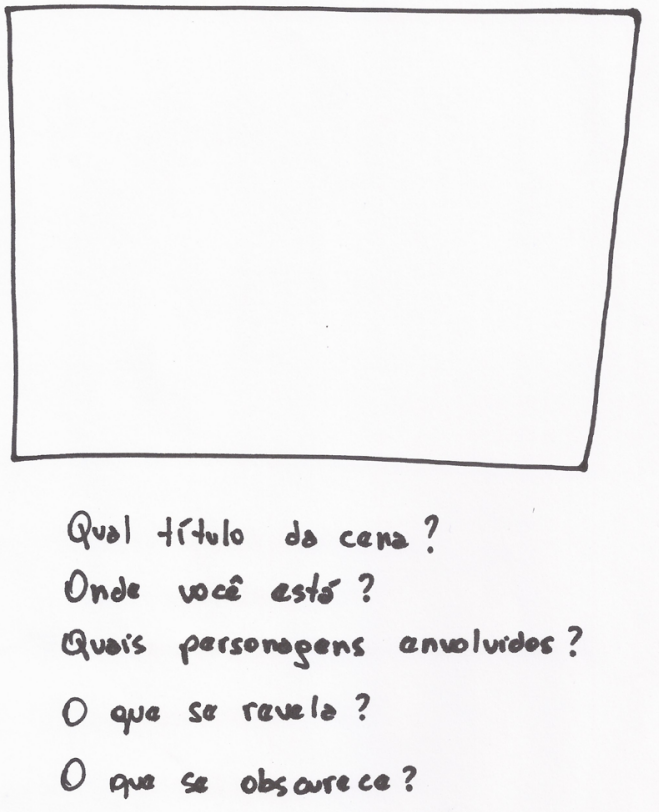

Tal experiência mostrou que era possível viver a cena não só como um espaço de projeção, mas também de revelação e por que não, de obscurescência para os conteúdos daquele que a faz, desfalecendo os pressupostos do teatro tão somente como um lugar de representação. 
PORTO ARTE



Revista de Artes Visuais

v. 25 n. 44 Jul/dez 2020 e-ISSN: 2179-8001

Figura 6: Cena Corpo - Cena Véu I (2020). Fonto: Maíra Gerstner

Figura 7: Túnel Casa (2020) Foto: Maíra Gerstner
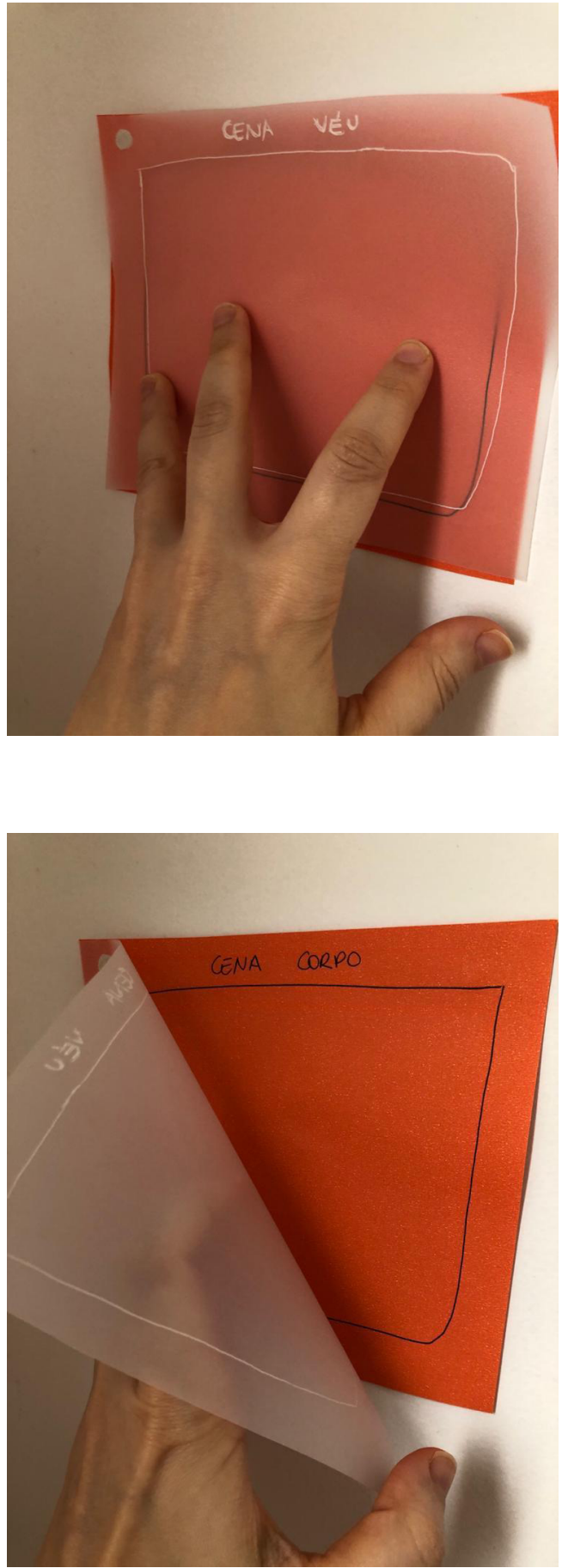


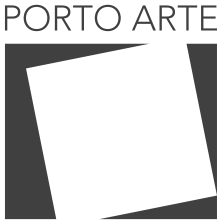

Revista de Artes Visuais

v. 25 n. 44 $\mathrm{Jul} / \mathrm{dez} 2020$ e-ISSN: 2179-8001
Figura 8: Túnel Foto: Maíra Gerstner

\section{Cena 3: 0 enterro não realizado}

Quando veio a pandemia Maria $^{2}$ se separou. Foi morar só, depois de dez anos de relacionamento. Ao passo que se compreendia em um novo contexto, também fazia seu luto, em meio a um luto coletivo devido às mortes diárias que se davam no país.

Alguns meses antes da pandemia, ela trouxe para a sessão o relato de uma participação em uma oficina de butoh. 0 gesto que ela havia encontrado lá, fruto de uma experiência de limpeza do chão me chamou a atenção: era um torcer de pano muito centrado no coração, muito enraizado e apropriado.

Ao passar das sessões esse gesto era eventualmente evocado por mim, seja através da fala, no que diz respeito a chamá-la a atenção para aquilo que ela sentia e que a enraizava; seja através do convite para que ela o fizesse novamente no contexto da sessão.

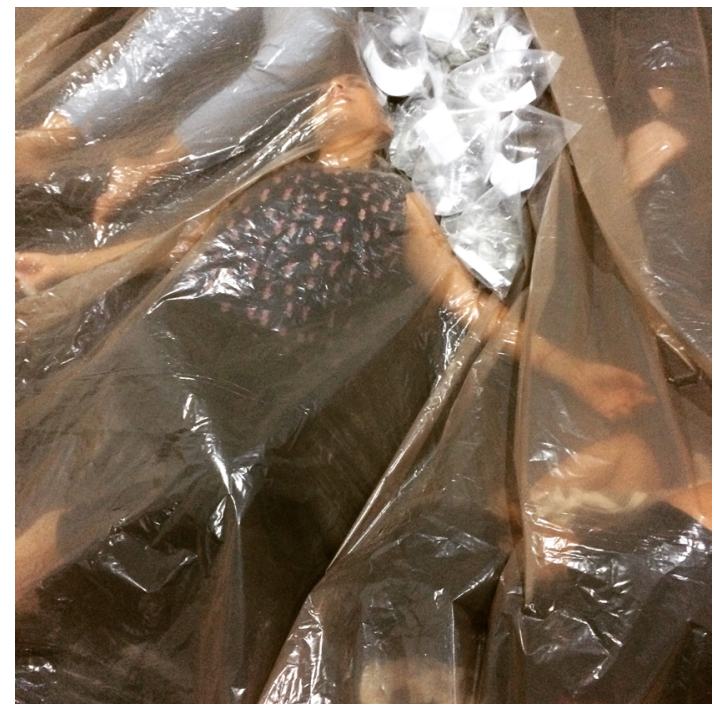

A memória e a presença do ex-companheiro ainda eram muito próximas, por mais que ela relatasse incômodo e desejo de deslocamento. Um dia propus: vamos enterrá-lo? Senti que a ação simbólica de enterrar esse alguém pudesse colaborar no processo de elaboração da separação.

Combinamos de fazê-lo na próxima sessão de grupo, que aconteceria dali três dias. No entanto, no dia marcado, outros conteúdos vieram à tona, entre eles a dificuldade em pensar em enterrar o ex-companheiro. Minha fala sempre se deu no sentido de pensarmos na potência da dimensão simbólica daquele ato. Porém, naquele dia, em prantos, ela dizia: acho que não quero enterrá-lo. 0 grupo fez então naquele dia, cartografias pessoais sobre o que cada uma tinha desejo de enterrar. Mas não realizaram o enterro propriamente dito.

2- Nome criado para o presente texto. 




Revista de Artes Visuais

v.25 n 44 $\mathrm{Jul} / \mathrm{dez} 2020$ e-ISSN: 2179-8001

Não atuaria a morte, na peça de nossas vidas, como uma personagem que se apresenta numa perspectiva inversa? Pois, se olharmos para ela de forma tão próxima, como uma presença que não existe mais, menos condição temos de compreendê-la. Mas, se podemos nos aproximar dela, da sua imensidão invisível, não estaríamos nos aproximando e podendo atribuir à sua atuação outras gamas de sentido?

Epílogo: A morte entrou em cena como revelação, em minha vida, a partir da morte das matriarcas, redimensionando minha pequenez e lembrando que ela nos faz a todos teatrais. Depois, na clínica, pude acompanhar uma pessoa que, ao compartilhar uma experiência de Teatro da Alma com algumas convidadas, passou a se sentir mais fortalecida a falar da morte do pai. E, ao propor um enterro simbólico em outro contexto clínico, percebi que a cena, dentro do contexto do Teatro da Alma, tem muitas formas de acontecer.

$\mathrm{Na}$ tentativa de materializar, espacialmente, o mistério que muitas vezes a cena revela no espaço da clínica, foram feitas algumas anotações, esquemas, fotos e experiências visuais que buscam traduzir aquilo que se dá entre os corpos, entre o visível e o invisível. 


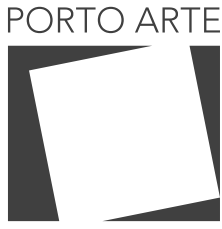

Revista de Artes Visuais

v.25 n.44

Jul/dez 2020 e-ISSN: 2179-8001

Texto submetido em: 11/11/2020 Texto publicado em: 19/11/2020

\section{Maíra Gerstner}

Artista, educadora e psicoterapeuta. É doutoranda em Artes Cênicas pela Universidade de São Paulo. Tem formação em Psicomotricidade Relacional Somática pelo Instituto Anthropos de Psicomotricidade (Rio de Janeiro) e Psicogenealogia pelo Lienspsy (França). É graduada em Artes Cênicas pela Universidade de São Paulo e mestre em Comunicação pela Universidade Federal do Rio de Janeiro. Foi professora temporária nos cursos de Artes Cênicas da UFRJ (2015-2016) e da Unesp (2019). Oferece workshops, cursos e atendimentos individuais e em grupo pela Fios do Ser (www.fiosdoser.com.br). 